SCIREA Journal of Biology

http://www.scirea.org/journal/Biology

June 23, 2021

Volume 6, Issue 3, June 2021

\title{
A Detection of Water-borne Bacterial and Protozoal Pathogens in Costa Rica, Guatemala, and the USA
}

\author{
Konstantina Stavroulaki ${ }^{1}$, Catherine Santanello ${ }^{2}$ \\ ${ }^{1}$ Washington University, St. Louis, Missouri \\ ${ }^{2}$ Southern Illinois University Edwardsville School of Pharmacy, Edwardsville, Illinois \\ Email: konstantina@wustl.edu (Konstantina Stavroulaki), csantan@siue.edu (Catherine \\ Santanello)
}

\begin{abstract}
The World Health Organization has emphasized the importance of screening water used for agricultural purposes in order to prevent potential waterborne and foodborne outbreaks. ${ }^{1}$ These outbreaks are linked to a variety of pathogens, especially Gram-negative bacteria, protozoa, and viruses. Pathogenic strains of Escherichia coli and Giardia lamblia have been shown to be leading causative agents of waterborne and foodborne infections in the U.S. and worldwide. ${ }^{1}$ The purpose of this investigation was to detect the presence of these species in water collected from irrigation points and other municipal sources found in Costa Rica, Guatemala, and the U.S. Another goal of this project was to evaluate the long-term efficacy of portable water filtration systems by screening for pre- or post- bacterial pathogens found in water samples. Results are based on polymerase chain reaction, gel electrophoresis, and direct immunofluorescence microscopy techniques to identify the microorganisms in our samples.

Overall, of the E. coli strains tested (Enteropathogenic/EPEC, Enterohemorrhagic/EHEC, Enteroaggregative/EAEC, and Enterotoxigenic/ETEC), we detected the EPEC and EHEC
\end{abstract}


strains in our sample pool. In specific, we concluded that $75 \%$ of our water samples collected from international and domestic locations were positive for EPEC, and $8 \%$ of our samples were positive for EHEC. Regarding G. lamblia, we found all samples collected from Costa Rica and the United States positive for the protozoan. Finally, nearly all (89\%) of the filters cleared all E. coli contaminants.

Keywords: water-borne pathogens, E. coli strains, Giardia lamblia, agricultural water

\section{Importance}

Millions of people do not have access to clean water, and poor water quality has been strongly associated with the presence of pathogenic microorganisms such as E. coli and G. lamblia. ${ }^{1}$ Health consequences of contaminated water consumption include the manifestation of UTI, diarrhea, dysentery, along with dehydration. In rare cases, these waterborne pathogens are associated with meningitis, sepsis, and even death. ${ }^{1}$ One of the goals of this investigation was to survey which strains of $E$. coli are most prevalent in each geographical location and if there is the presence of G. lamblia, with the ultimate purpose of conducting an epidemiological study resulting in public awareness in the target regions. We also compared pre-and postfiltered water to test for the effectivity of portable water filtration systems so that their use can be an alternative to costlier water filtration systems or used in areas without any filtration methods at all.

Drinking-water. (n.d.). Retrieved July 21, 2020, from https://www.who.int/newsroom/fact$\underline{\text { sheets/detail/drinking-water }}$

\section{Introduction}

It is estimated that approximately 663 million people worldwide do not have access to clean water. ${ }^{1}$ Poor water quality has been strongly associated with the presence of pathogenic microorganisms. When people consume contaminated water, they are exposed to numerous health hazards related to these microbes. ${ }^{2}$ Critical health consequences of contaminated water consumption include the manifestation of urinary tract infections, diarrhea, dysentery, and dehydration. Diarrhea is a leading cause of morbidities and fatalities among children under the age of 5 years-old worldwide. ${ }^{3}$ Based on the Center for Disease Control and Prevention 
(CDC), it is estimated that 2,195 children die daily due to diarrheal disease from drinking unpotable water or consuming water-contaminated agricultural products. ${ }^{4}$

Agricultural water comes from surface water sources such as irrigation points, streams, rivers, and man-made lakes. Major concerns regarding the use of agricultural water include microbial and chemical contamination, which can cause illnesses to the consumers. The World Health Organization has emphasized the importance of screening water used for agricultural purposes in order to prevent potential waterborne and foodborne outbreaks. ${ }^{5}$ E. coli, Salmonella $\underline{s p p}$, Shigella dysenteriae, G. lamblia, Cryptosporidium parvum, norovirus, and Hepatitis A are examples of major causative agents of documented outbreaks. ${ }^{2}$ These microorganisms can be transmitted to animal reservoirs and humans, causing mild to severe foodborne illnesses.

The purpose of this study was to determine the frequency of some of the most prevalent bacterial and protozoal pathogens associated with areas of microbial water contamination of water irrigation sources in the Midwestern U.S., as well as selected locations in Costa Rica and Guatemala. Our major focus was on the leading strains of the bacterium, E. coli (Enteropathogenic/EPEC, Enterohemorrhagic/EHEC, Enteroaggregative/EAEC, and Enterotoxigenic/ETEC), as well as the protozoal contaminant, G. lamblia. We also compared pre-and post-filtered water to test for the effectivity of portable water filtration systems that can be recommended for use in areas of moderate to severe water contamination.

What makes these species such a threat to the human health? EPEC is a significant cause of diarrhea and even death among the pediatric population, mainly in the developing world. ${ }^{6}$ The appearance of distinguishing attaching-effacing lesions is considered a hallmark mechanism of the EPEC pathogenesis. ${ }^{6}$ EHEC is a highly dangerous $\underline{E}$. coli strain as it produces potent Shiga-toxins that can cause bloody diarrhea and other life-threatening complications. ${ }^{6}$ EAEC is a common cause of acute or chronic pediatric diarrhea. ${ }^{7}$ EAEC bacteria infect the host by forming a characteristic biofilm that degrades the microvilli. ${ }^{7}$ ETEC is predominantly known to cause traveler's diarrhea and disrupt the intestinal mucosa by generating heat-stable (ST) toxins and heat-labile (LT) toxins. ${ }^{6}$ Giardiasis is one of the most prevalent waterborne illness, with 1.2 million cases reported annually. ${ }^{8}$ The clinical presentation of giardiasis varies from asymptomatic carriage to severe diarrhea, abdominal pain, nausea, vomiting, and general malaise. ${ }^{8}$ Giardia cysts are resistant to disinfection and can survive for weeks to months in cold water and can damage the brush border, cause enzyme deficiencies, and reduction of nutrient absorbance potential. ${ }^{8}$ 


\section{Methods}

Water samples were collected from selected locations (see appendix) from the Reventazon River (Cartago, Costa Rica), Lake Atitlan (Panajachel, Guatemala), Missouri River (St. Louis County, Missouri), and Shoal Creek (Madison and Bond County, Illinois). These locations were chosen because of their association with irrigation systems for agricultural purposes. Although most developed countries such as the U.S and Costa Rica have well-established water purification systems for drinking water and home use, water used for irrigation purposes is often unmonitored in many parts of the world. The categorizations of the water sampling locations are listed in the following table:

Table 1. "Selected Sampling Locations for the Presence of E. coli and G. lamblia"

\begin{tabular}{|cc|}
\hline Location & Sampling Source \\
\hline Reventazon River, Costa Rica & River \\
\hline Lake Atitlan, Guatemala & Lake \\
\hline Missouri River, Missouri & River \\
\hline Shoal Creek, Illinois & Stream \\
\hline
\end{tabular}

$100 \mathrm{~mL}$ of water was collected from each sampling point. Freshwater samples were tested for the presence of E. coli using Portable Water Quality Test Kits (Aquagenx, LCC). $100 \mathrm{~mL}$ of freshly collected water samples was transferred in a Thio bag, and a growth medium tablet was dissolved into the water for 10 minutes. Then, $100 \mathrm{~mL}$ of medium-treated water were transferred into the compartment bag for incubation. The samples were incubated at $37 \mathrm{C}$ for 24 hours and scored for the presence of E. coli based on the "Most Probable Number" table provided by the manufacturer. After the incubation, yellow-brown-colored samples were determined negative for E. coli, whereas blue-green-colored samples were positive for E. coli. Of note, this test only indicates the presence or absence of $E$. coli strains, and it is not indicate the specific strain of $E$. coli or the exact microbial quantity.

The DNA of each E. coli positive sample was extracted with a DNeasy kit (Qiagen). We used Polymerase Chain Reaction (PCR) to determine the presence of the pathogenic E. coli strains in the extracted DNA. The same protocol was followed to examine the presence of $E$. coli in pre- and post-filtration water samples using new filters and pre-used filters preserved for three and six months. 
The following reagents were utilized to prepare the PCR samples: $10 \quad$ L of DreamTaq ${ }^{\mathrm{TM}}$ Green PCR Master Mix (Thermo Fisher Scientific), 6 L of deionized water (collected from the Pharmaceutical sciences laboratory deionized water source), 1 L of forward primer and 1 L of its respected reverse primer (Macrogen), and 2 L of the DNA sample being investigated. In addition, positive control samples (AATC) were made containing their respective E. coli DNA samples, and negative controls containing deionized water only. ${ }^{9}$ The diagnostic targets and primers selected for this investigation are documented in the following table. $^{9}$

Table 2. "Diagnostic Targets for PCR Classified by E. coli Pathotype" 9

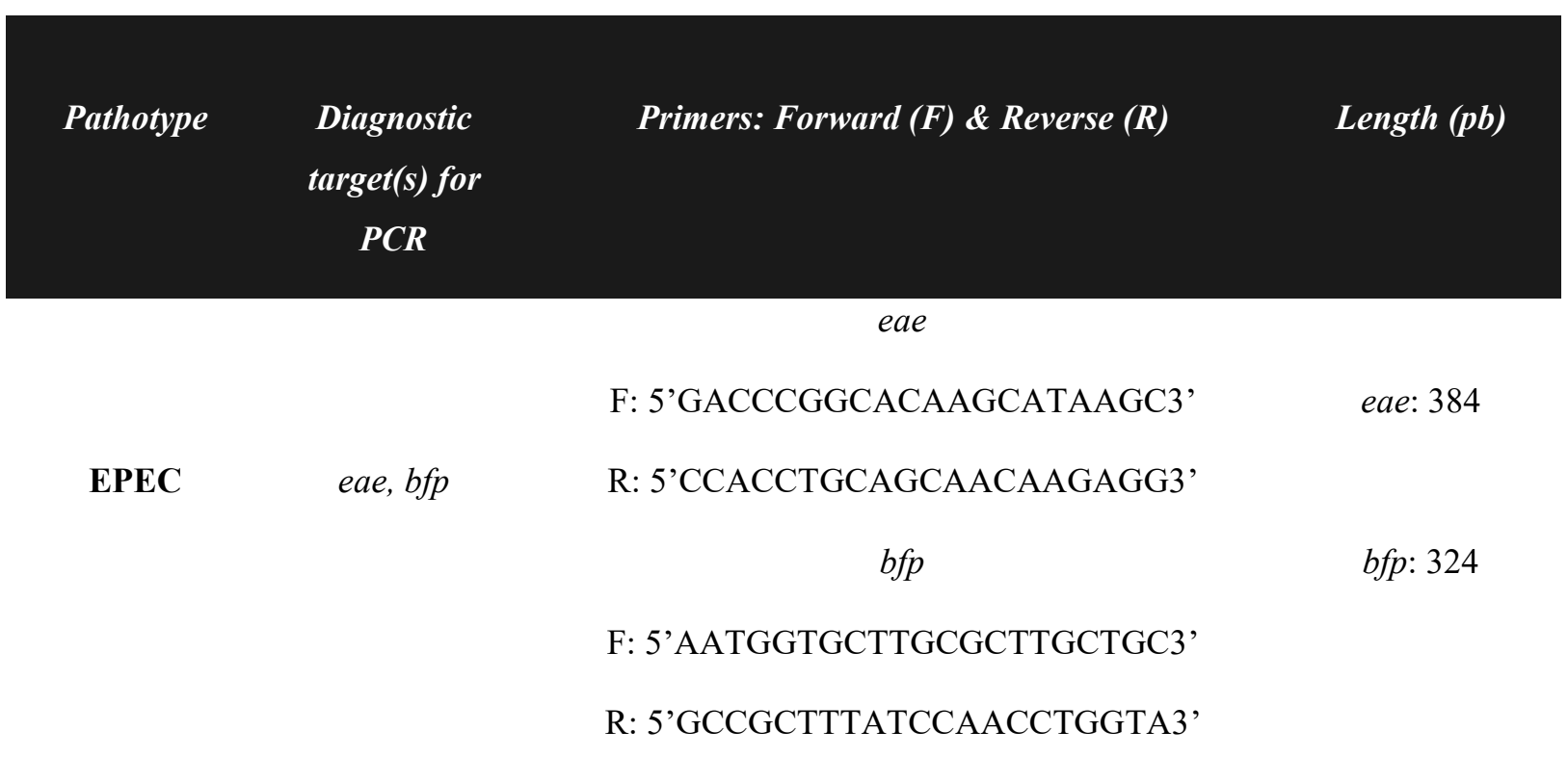

stx 1

F: 5'CTGGATTTAATGTCGCATAGTG3' stx1: 150

EHEC stx 1, stx2 R: 5'AGAACGCCCACTGAGATCACTC3'

stx2

stx2: 250

F: 5'GGCACTGTCTGAAACTGCTCC3'

R: 5'TCGCCAGTTATCTGACATTCTG3'

$l t$

ETEC $l t, s t \quad$ F:5'TCTCTATGTGCATACGGAGC3' $l t: 322$

R:5'CCATACTGATTGCCGCAAT3'

$s t$

st: 186

F: 5'TCTGTATTGTCTTTTTCACC3' 


\section{F: 5'CTGGCAAAAGACTGTATCAT3'}

EAEC

aatA

R: 5'CAATGTATAGAAATCCGCTGTT3'

aatA: 630

The samples were then transferred to a SimpliAmp ${ }^{\mathrm{TM}}$ thermal cycler (Thermo Fisher Scientific) for DNA amplification. The following settings depicted in Table 2 were utilized. ${ }^{9}$ The procedure was repeated for 35 cycles, with a total time of 1 hour and 22 minutes per PCR run.

Table 3. "PCR Settings for the Investigation of E. coli Pathotypes" 9

\begin{tabular}{|c|ccc|}
\hline $\begin{array}{c}\text { Step of DNA Amplification } \\
\text { Initial Denaturation }\end{array}$ & Temperature & Time \\
Denaturation & 94 & $\mathrm{C}$ & 5 minutes \\
Annealing & 94 & $\mathrm{C}$ & 30 seconds \\
Extension & 56 & $\mathrm{C}$ & 30 seconds \\
Final Extension & 72 & $\mathrm{C}$ & 30 seconds \\
\hline
\end{tabular}

After DNA amplification, the samples were loaded onto an agarose gel with $2 \%$ ethidium bromide. An E-Gel low-range quantitative DNA ladder (Thermo Fisher Scientific) was loaded into the first lane of the gel. Each gel was analyzed using the Bio-Rad Chemi DocTm XRS instrument using the Image Lab software. The detected bands were compared with the ladder and the positive control to determine presence of the target genes and overall presence of each pathogen.

Due to an insufficient amount of water collected in Guatemala, only samples collected in Costa Rica and in Illinois were tested for G. lamblia. $100 \mathrm{~mL}$ of water samples were centrifuged and the solid residue was filtered using an analogous syringe and filtration apparatus (Thermo Fisher Scientific). The filter was gently removed from the filtration apparatus and washed with $20 \mu \mathrm{L}$ of phosphate buffered saline solution (PBS). The filter was then scraped in a sterilized microbiological plate in order to remove G. lamblia cysts, which were potentially trapped on the filter. Five $\mu \mathrm{L}$ of each filtered sample was placed on each well .The samples on the slide were allowed to air-dry for a minimum of 10 minutes, fixed with acetone for 10 minutes, and air-dried for 10 minutes. A direct anti-G. lamblia fluorescein monoclonal antibody (LS Bio) was diluted 1:10 in phosphate buffered saline and $10 \mu \mathrm{L}$ of 
the antibody was added on each water sample located on the slide. The slide was placed in a moist chamber and incubated at $37{ }^{\circ} \mathrm{C}$ for 45 minutes. Upon completion of incubation, the slide was rinsed in three different chambers of phosphate buffered saline solution for a total of 20 minutes. Finally, the slide was mounted with glycerol. Positive and negative control slides were generated following the protocol described and using a positive G. lamblia sample (ATCC) and deionized water respectively. ${ }^{10}$ Slides were examined with a standard fluorescence microscope and digitally analyzed using MetaMorph software version 7.8.13.O.

\section{Results}

We tested twelve water samples for the presence of E. coli: five from Costa Rica, two from Guatemala, five from the US (four from Illinois, and one from Missouri). We tested samples in triplicate to confirm our results. Overall, we found that $25 \%$ of our samples were positive for the eae gene (Enteropathogenic E. coli), and $75 \%$ of our samples were positive for the $b f p$ gene (Enteropathogenic E. coli). In addition, only $25 \%$ of our samples were found positive for both virulence genes of Enteropathogenic E. coli. None of the samples were found positive for the stxl gene (Enterohemorragic E. coli), and $8 \%$ of the samples were found to be positive for the stx2 gene (Enterohemorragic E. coli). None of the samples were found positive for both Enterohemorragic E. coli genes. With respect to the Enterotoxigenic and Enteroaggregative E. coli genes, all the samples were negative for both $l t$ and st genes, and aatA gene. The following table summarizes our findings.

Table 4. "Detection Frequency (\%) of E. coli Genes in Water Samples Collected in Costa Rica,

\section{Guatemala, Illinois, and Missouri”}

\begin{tabular}{|c|c|c|c|c|c|}
\hline $\begin{array}{l}\text { E. coli } \\
\text { Strain }\end{array}$ & $\begin{array}{l}\text { Examined } \\
\text { Genes }\end{array}$ & $\begin{array}{c}\text { Frequency \% in } \\
\text { Costa Rica }\end{array}$ & $\begin{array}{l}\text { Frequency \% in } \\
\text { Guatemala }\end{array}$ & $\begin{array}{c}\text { Frequency \% in } \\
\text { the USA }\end{array}$ & $\begin{array}{c}\text { Overall } \\
\text { Frequency \% }\end{array}$ \\
\hline EPEC & eae & $0 \%$ & $0 \%$ & $60 \%$ & $25 \%$ \\
\hline EPEC & $b f p$ & $60 \%$ & $50 \%$ & $100 \%$ & $75 \%$ \\
\hline EPEC & $e a e+b f p$ & $0 \%$ & $0 \%$ & $60 \%$ & $25 \%$ \\
\hline EHEC & stx 1 & $0 \%$ & $0 \%$ & $0 \%$ & $0 \%$ \\
\hline EHEC & stx 2 & $20 \%$ & $0 \%$ & $0 \%$ & $8 \%$ \\
\hline EHEC & $s t x 1+s t x 2$ & $0 \%$ & $0 \%$ & $0 \%$ & $0 \%$ \\
\hline
\end{tabular}




\begin{tabular}{cccccc}
$\boldsymbol{E}$ TEC & $\boldsymbol{l t}$ & $0 \%$ & $0 \%$ & $0 \%$ & $0 \%$ \\
\hline $\boldsymbol{E T E C}$ & $\boldsymbol{s t}$ & $0 \%$ & $0 \%$ & $0 \%$ & $0 \%$ \\
\hline $\boldsymbol{E T E C}$ & $\boldsymbol{l t}+\boldsymbol{s t}$ & $0 \%$ & $0 \%$ & $0 \%$ & $0 \%$ \\
$\boldsymbol{E} \boldsymbol{E} \boldsymbol{E} \boldsymbol{E C}$ & $\boldsymbol{a a t \boldsymbol { A }}$ & $0 \%$ & $0 \%$ & $0 \%$ & $0 \%$ \\
\hline
\end{tabular}

Since most of our samples were positive for EPEC, we conducted categorical analysis using the Fisher's exact test to further analyze the presence of EPEC in our sample pool. Based on the p-value $>0.05$, we conclude is that there is not a statistically significant association between the geographic locations of the sampling and the presence of EPEC. The following table depicts the Fisher's exact test.

Table 5. "Fisher's Exact Test for the Presence of EPEC in Domestic and International Locations"

\begin{tabular}{cccc|}
\hline Region & EPEC Positive & EPEC Negative & Total \\
\hline Domestic & 5 & 0 & $5(\mathbf{4 1 . 6 6 \% )})$ \\
\hline International & 4 & 3 & $7(\mathbf{5 8 . 3 3 \% )}$ \\
Total & $9(\mathbf{7 5 \%})$ & $3 \mathbf{( 2 5 \% )}$ & $12(\mathbf{1 0 0 \% )}$
\end{tabular}

P-value: 0.320

We tested 15 pre-filtrated water samples for the presence of G. lamblia, six collected in Costa Rica and nine collected in southern Illinois. All water samples tested for G. lamblia were found positive.
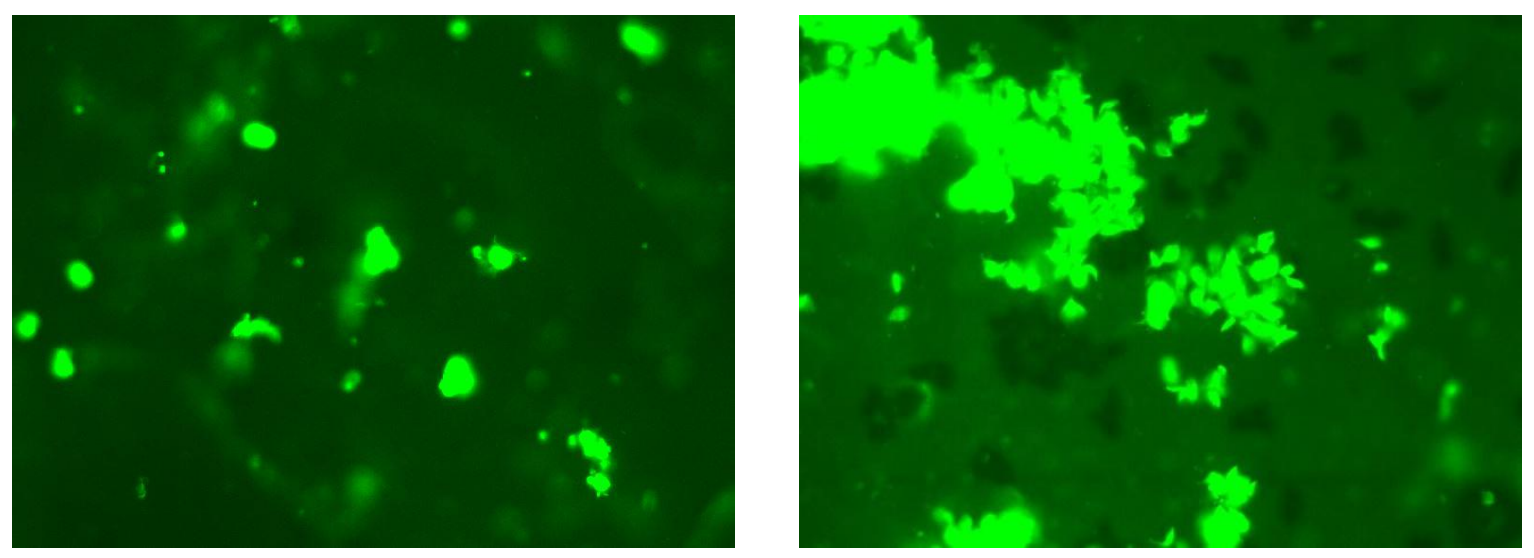

Figure 1.“'Clumps of G. lamblia Cysts Captured at Pharmaceutical Sciences Laboratory (SIUE) Using Direct Immunofluorescence Microscopy."

Positive Control (Left) \& Water Sample Collected in Southern Illinois (Right) 
We evaluated the short and long-term effectivity of Sawyer Products Water Filtration Systems ${ }^{\circledR}$, which are often used in the removal of these and other potential contaminants in drinking water. We conducted an analysis regarding the presence of E. coli in an additional 18 pre- and post-filtration water samples using new filters and pre-used filters preserved for three and six months. We tested the respective filters from samples in Costa Rica and the USA. The Sawyer filters can filter up to $400 \mathrm{~mL}$ of water at a time. All 18 pre-filtration water samples were heavily contaminated with E. coli. Of the 18 post-filtration samples, two post-filtration samples presented with E. coli microorganisms. Based on our results, we conclude that $89 \%$ of Sawyer filters were able to clear the majority of E. coli contaminants present in the samples. We conducted a categorical analysis to evaluate the Sawyer filtration units based on their status of usage (new or old) and their ability to clear the pathogenic contaminants. Based on the p-value $>0.05$, we failed to reject the null hypothesis, and the conclusion is that there is not a statistically significant association between the age of the filter and its ability to clear $E$. coli contaminants. The following table depicts the Fisher's exact test regarding our evaluation of the filters.

Table 6. "Fisher's Exact Test for the Evaluation of Sawyer Filtration Units based on their Status of

\section{Usage"Discussion}

\begin{tabular}{cccc} 
Type of Filter & E. coli Positive & E. coli Negative & Total \\
\hline New & 2 & 7 & $9(\mathbf{5 0 \%})$ \\
Used & 0 & 9 & $9(\mathbf{5 0 \%})$ \\
Total & $2(11 \%)$ & $16(\mathbf{8 9 \%})$ & $18(\mathbf{1 0 0 \% )}$
\end{tabular}

P-value: 0.471

We detected EPEC in $75 \%$ of our water samples and EHEC in $8 \%$ of our water samples from both international and local (Missouri/Illinois) sampling sites. We did not find any samples contaminated with either ETEC or EAEC. Interestingly, regarding EPEC, most of our samples were positive for the $b f p$ gene only, without the co-existence of the eae gene. Typical EPEC microorganisms contain both the eae gene and the bfp gene, and the ones that present the eae gene, but lack the $b f p$ gene, are classified as atypical EPEC strains. ${ }^{11}$ The possible pathogenesis or classification regarding the presence of $b f p$ gene alone, without the copresence of eae gene, is not well established yet. Singh et al. identified samples in India, Iran, and South Africa in which only the presence of the $b f p$ gene was confirmed. ${ }^{12}$ Our findings 
also confirm the possibility of the existence of only the $b f p$ gene without the co-presence of the eae gene.

Another interesting result of our study was that we were not able to detect any ETEC strains, and only one of our samples from Costa Rica was positive for EHEC. This was unexpected considering that the CDC states that most foodborne are due to EHEC and ETEC, posing a tremendous threat in the developing world. ${ }^{13}$ Since ETEC is the most common cause of diarrhea in travelers to so many endemic regions, a major focus in the development of a vaccine is ETEC based. ${ }^{14}$

G. lamblia is the most common protozoan gastrointestinal parasite worldwide, with infectivity rates as high as $50 \%$ in developing countries. ${ }^{15}$ Giardia cysts are typically detected in water and fecal samples using PCR, flow cytometry (FCM), or immunofluorescence assays (IFA). ${ }^{16}$ Using direct immunofluorescence, we detected G. lamblia cysts in all samples we tested for the protozoan based on shape, size, and degree of FITC-fluorescence. Giardia cysts are resistant to disinfection and can survive for weeks to months in cold water, which is potentially one of the reasons for their common prevalence in water. ${ }^{8}$ While not as serious clinically as many waterborne pathogenic disorders, giardiasis has been linked to numerous outbreaks of foodborne gastroenteritis and traveler's diarrhea. Hence, the presence of $G$. lamblia in all of our samples was not surprising and it confirms that it is a very ubiquitous waterborne threat.

We concluded that $89 \%$ of the Sawyer filters were able to clear a high number of $E$. coli contaminants, which makes the presence of it undetectable based on our assay. Despite using careful aseptic techniques, it is unclear if the 2 post-filtration samples that did not clear the bacteria were contaminated due to a cross-contamination error or due to defective filters. Further evaluation of the Sawyer filtration systems is needed in order to make strong recommendations regarding their long-term effectivity against E. coli, and other common waterborne pathogens. So far, our findings indicate that the use of Sawyer filtration systems is promising since they are relatively inexpensive, portable, user-friendly, and can filter up to 100,000 gallons of water. ${ }^{17}$ In addition, they are less labor-intensive as they do not need installation the way that units such as bio-sand filtration systems require. Because there is a lack of potable drinking water and an overwhelming number of deaths caused by contaminated water worldwide, the utilization of systems like these can make a difference in the mortality rates due to this preventable infectious disease. 


\section{Discussion and Limitations}

Our results confirm that strains of E. coli and G. lamblia continue to be waterborne threats in many parts of the world. This shows the need for organizations like the World Health Organization to focus on freshwater quality in developing countries and vaccines that target common waterborne pathogens in these areas. Since viral pathogens, such as norovirus and Hepatitis A, ${ }^{18,19}$ as well as other bacterial species (e.g., Shigella dysenteriae) and protozoal species (e.g., Cryptosporidium parvum) are serious waterborne contaminants, these will be the focus of further studies. Filtration systems can provide protection against these pathogens in areas that do not have potable water. However, our sampling was limited to a relatively small number of water samples examined. Our original intent was to compare the results from these three countries with water samples from agricultural areas in Jacmel, Haiti, but because of travel restrictions due to political unrest, that was not possible. In addition, we did not determine the microbial quantity in our sample pool; rather we focused on presence/absence of the target microorganisms. By examining the quantity of microbes present in a sample, one can assess the potential microbial risk for emergence of illness regarding contamination with these pathogens. Real-Time PCR (RT-PCR) would be advantageous for this purpose.

Since the Portable Water Quality Test Kits are not a quantitative test and we were using a relatively small sample, there was no way to quantify the exact level of contamination or to verify that the filters were able to remove all contaminants. In addition, the Sawyer water filtration systems were only evaluated against E. coli. Further evaluation is needed regarding their long-term effectivity in clearing other threatening bacterial and protozoal contaminants. While we realize that the Sawyer filtration system is just one of many potential filtration units that can be utilized, they are being used by millions of people in over 80 developing countries for their daily clean water needs and by non-profits doing development work in water quality. ${ }^{20}$

\section{Conclusions}

Studies like this can contribute to scientific and public-awareness of the importance of removing waterborne contaminants from drinking water. This also highlights the need to examine irrigation water since contaminated foodborne outbreaks occur with relative frequency around the world. In addition, by investigating which waterborne pathogens are common to each geographic region, we could use this information to augment vaccine 
development in the field of infectious diseases transmitted by contaminated water, particularly in areas where the death rate is high due to the ingestion of unpotable water. Broadening the scope this research to include more bacterial and protozoal pathogens, in addition to viral ones, is needed. In addition, by conducting long-term evaluations of a variety of water filtration units, recommendations regarding their use can be useful to organizations that work with improving the quality of water in countries that continuously struggle with this lifethreatening issue.

\section{Appendix}

The following figures depict the target areas of water collection.

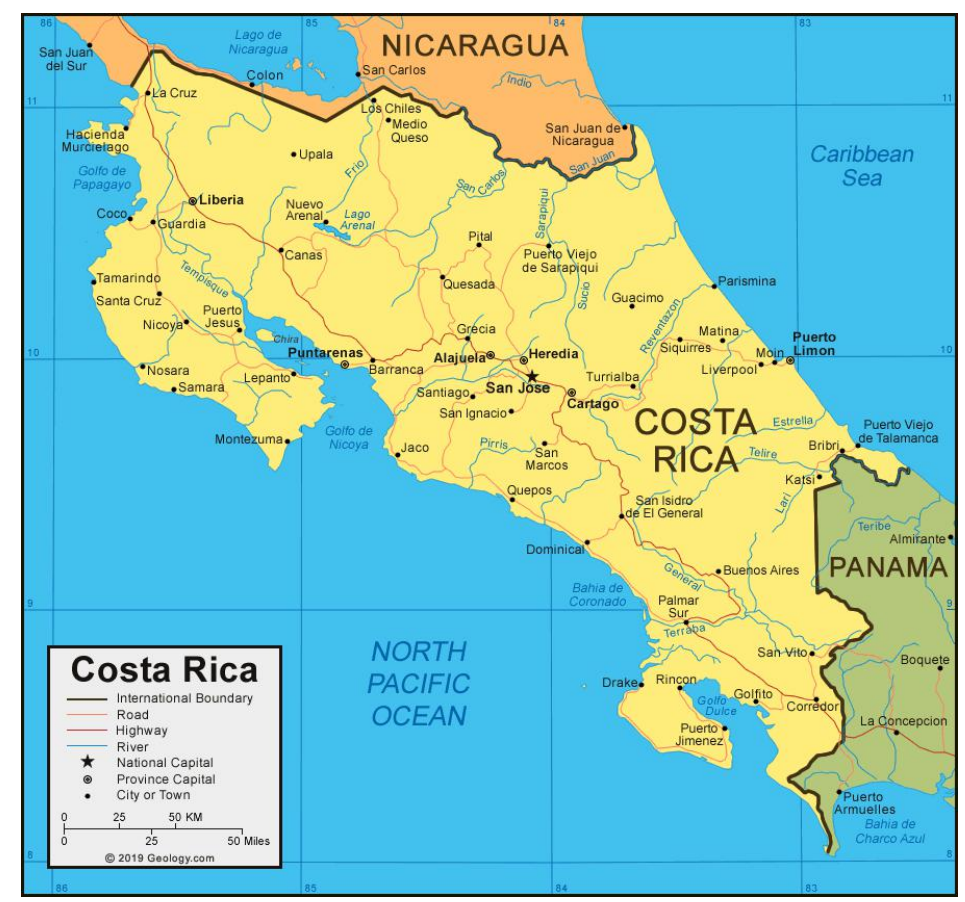

Figure 1. "Reventazon River, Costa Rica"21 


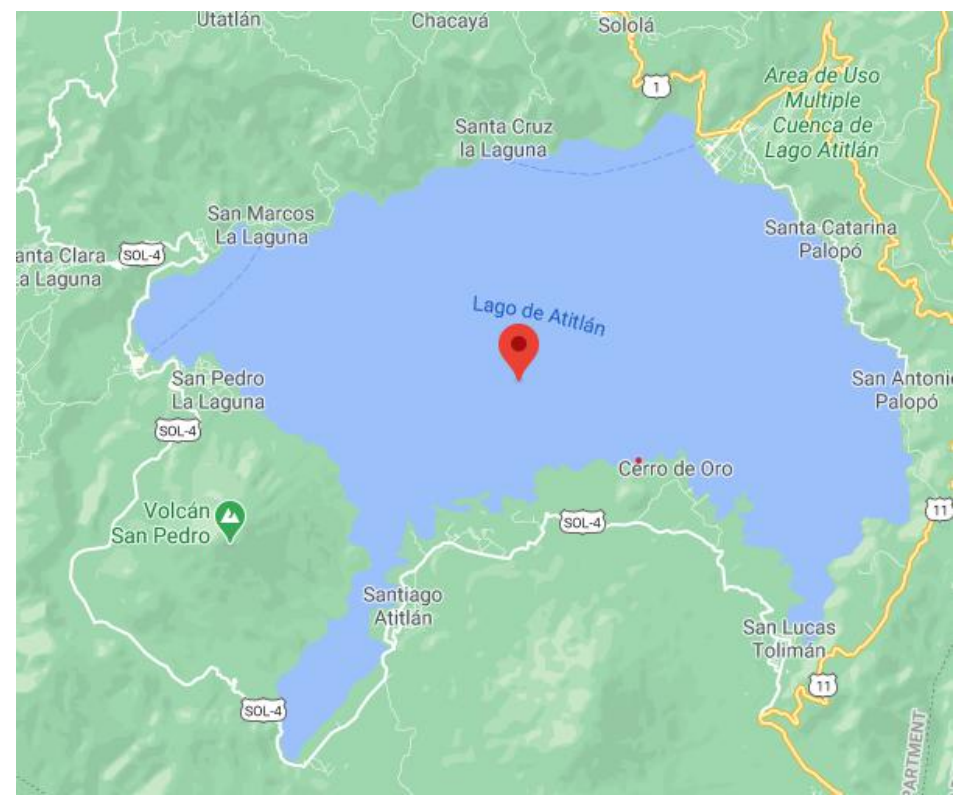

Figure 2. "Lake Atitlan, Guatemala"22

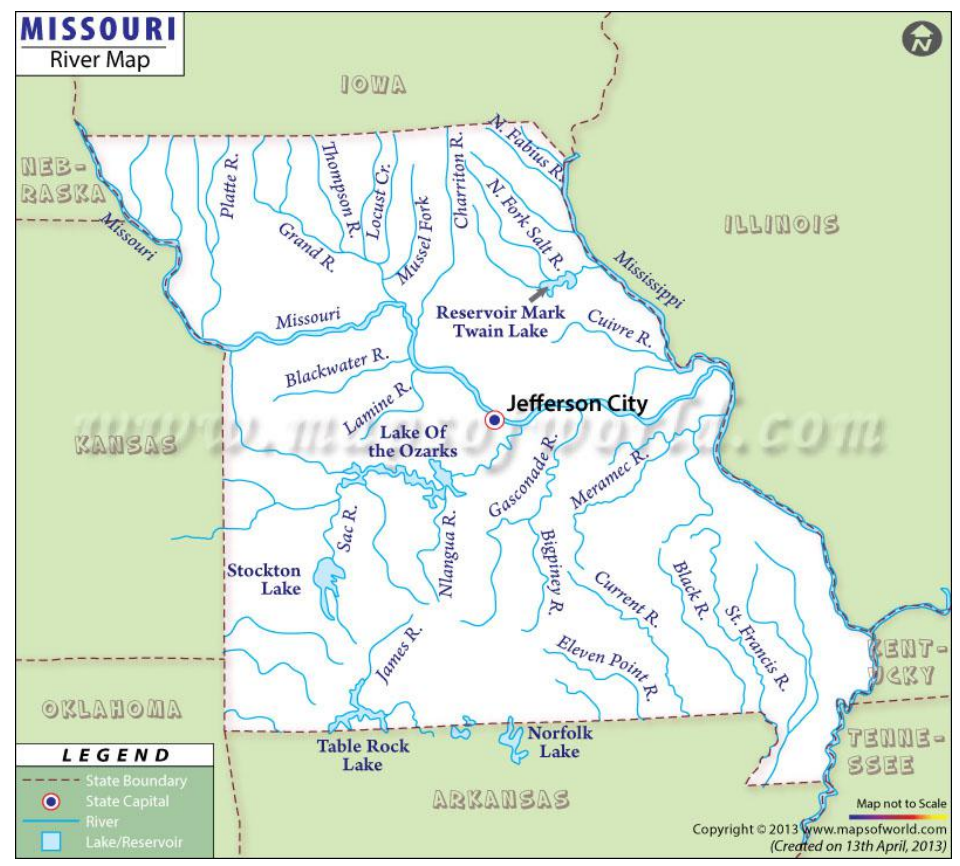

Figure 3. "Missouri River, St. Louis, MO"23 


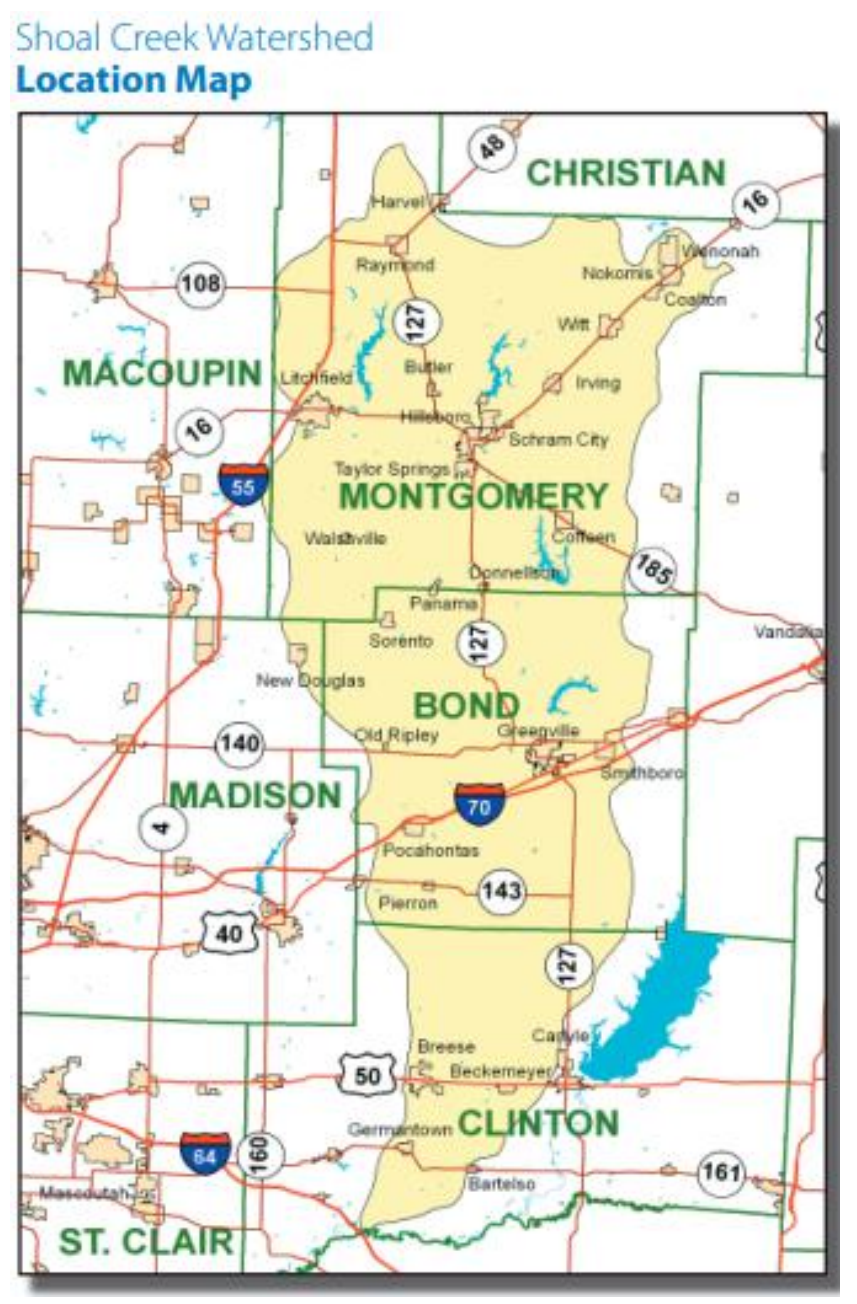

Figure 4. "Shoal Creek, Illinois. The sampling locations included the following cities: Pocahontas, Sorento and Silver Creek"24

\section{References}

[1] Drinking-water. Retrieved July 21, 2020, from https://www.who.int/newsroom/factsheets/detail/drinking-water

[2] Percival, S. L. (2004). Microbiology of waterborne diseases. Amsterdam: Elsevier Academic Press.

[3] Liu, L., Oza, S., Hogan, D., Perin, J., Rudan, I., Lawn, J., . . Black, R. (2014, September 30). Global, regional, and national causes of child mortality in 2000-13, with projections to inform post-2015 priorities: An updated systematic analysis. Retrieved July 21, 2020, from https://www.sciencedirect.com/science/article/pii/S0140673614616986

[4] Global Diarrhea Burden. (2015, December 17). Retrieved July 21, 2020, from https://www.cdc.gov/healthywater/global/diarrhea-burden.html

[5] Water-related diseases. (2016, August 29). Retrieved July 21, 2020, from https://www.who.int/water_sanitation_health/diseases-risks/diseases/diarrhoea/en/ 
[6] Robins-Browne, R. M., Holt, K. E., Ingle, D. J., Hocking, D. M., Yang, J., \& Tauschek, M. (2016). Are Escherichia coli Pathotypes Still Relevant in the Era of Whole-Genome Sequencing? Frontiers in Cellular and Infection Microbiology, 6. doi:10.3389/fcimb.2016.00141

[7] Estrada-Garcia, T., Perez-Martinez, I., Bernal-Reynaga, R., \& Zaidi, M. B. (2014). Enteroaggregative coli: A Pathogen Bridging the North and South. Current tropical medicine reports, 1(2), 88-96. https://doi.org/10.1007/s40475-014-0018-7

[8] Giardia. (2015, July 22). Retrieved July 22, 2020, from https://www.cdc.gov/parasites/giardia/index.html

[9] Luz María Chacón, J., Lizeth Taylor, C., Carmen Valiente, A., Irene Alvarado, P., \& Ximena Cortés, B. (2012). A DNA Pooling Based System to Detect Escherichia coli Virulence Factors in Fecal and Wastewater Samples. Brazilian journal of microbiology: [publication of the Brazilian Society for Microbiology], 43(4), 1319-1326. https://doi.org/10.1590/S1517-838220120004000012

[10] Reppell Santanello, C. (1990). The Incidence of Pathogens of Lyme disease and Rocky Mountain Spotted Fever in Eastern Missouri. PhD Dissertation, St. Louis University.

[11] Ochoa, T. J., \& Contreras, C. A. (2011). Enteropathogenic Escherichia coli Infection in Children. Current Opinion in Infectious Diseases, 24(5), 478-483. doi:10.1097/qco.0b013e32834a8b8b

[12] Singh, T., Das, S., Ramachandran, V. G., Shah, D., Saha, R., Dar, S. A., \& Rai, A. (2017). Typical \& Atypical Enteropathogenic Escherichia coli in diarrhoea \& their Role as Carrier in Children Under Five. The Indian journal of medical research, 145(4), 551-557. https://doi.org/10.4103/ijmr.IJMR_25_15

[13] E. coli (Escherichia coli). (2020, February 26). Retrieved September 21, 2020, from https://www.cdc.gov/ecoli/index.html

[14] Chakraborty, S., Randall, A., Vickers, T. J., Molina, D., Harro, C. D., DeNearing, B., Brubaker, J., Sack, D. A., Bourgeois, A. L., Felgner, P. L., Liang, X., Mani, S., Wenzel, H., Townsend, R. R., Gilmore, P. E., Darsley, M. J., Rasko, D. A., \& Fleckenstein, J. M. (2018). Human Experimental Challenge with Enterotoxigenic Escherichia coli Elicits Immune Responses to Canonical and Novel Antigens Relevant to Vaccine Development. The Journal of infectious diseases, 218(9), 1436-1446. https://doi.org/10.1093/infdis/jiy312

[15] Behr, M. A., Kokoskin, E., Gyorkos, T. W., Cédilotte, L., Faubert, G. M., \& Maclean, J. D. (1997). Laboratory Diagnosis for Giardia lamblia Infection: A Comparison of 
Microscopy, Coprodiagnosis and Serology. The Canadian journal of infectious diseases = Journal canadien des maladies infectieuses, 8(1), 33-38. https://doi.org/10.1155/1997/270179

[16] Keserue, H. A., Füchslin, H. P., Wittwer, M., Nguyen-Viet, H., Nguyen, T. T., Surinkul, N., Koottatep, T., Schürch, N., \& Egli, T. (2012). Comparison of Rapid Methods for Detection of Giardia spp. and Cryptosporidium spp. (oo)cysts Using Transportable Instrumentation in a Field Deployment. Environmental science \& technology, 46(16), 8952-8959. https://doi.org/10.1021/es301974m

[17] Squeeze Water Filtration System: Sawyer Products. Retrieved September 22, 2020, from https://sawyer.com/products/sawyer-squeeze-filter/

[18] Foodborne viruses: What you need to know: Retrieved December $9^{\text {th }}, 2020$. http://foodsafety.merieuxnutrisciences.com/2014/10/17/foodborne-viruses-what-youneed-to-know/

[19] Maunula, L., Miettinen, I., von Bonsdorff, C.H. (2005). Norovirus outbreaks from drinking water. Emerging Infectious Diseases. 11(11): 1716-1721 doi: $10.3201 /$ eid1111.050487

[20] Water filtration. Retrieved December $9^{\text {th }}, 2020$. https://sawyer.com/water-filtration/

[21] Lake Reventazon. Retrieved December $9^{\text {th }}$, 2020.https://geology.com/world/costa-ricasatellite-image.shtml

[22] Lake Attitlan. Retrieved December $\quad 8^{\text {th }}$, 2020. https://www.google.com/maps/place/Lake+Atitl\%C3\%A1n/@14.6788048,91.2714047,12z/data=!3m1!4b1!4m5!3m4!1s0x85894ac7c083b493:0xa6e33f7d6b54910! $\underline{8 \mathrm{~m} 2 ! 3 \mathrm{~d} 14.6906713 ! 4 \mathrm{~d}-91.2025207}$

[23] Missouri $\quad$ River. $\quad$ Retrieved December $\quad 8^{\text {th }}$, 2020. https://www.mapsofworld.com/usa/states/missouri/missouri-river-map.html

[24] Shoal Creek Watershed. Retrieved December $8^{\text {th }}$, 2020. https://prod.nrcs.usda.gov/Internet/FSE_DOCUMENTS/nrcs141p2_030246.pdf 